\title{
THE PRINCETON REFERENCE DESIGN FUSION POWER PLANT
}

BY

WILLIAM G. PRICE, JR,

\section{PLASMA PHYSICS LABORATORY}

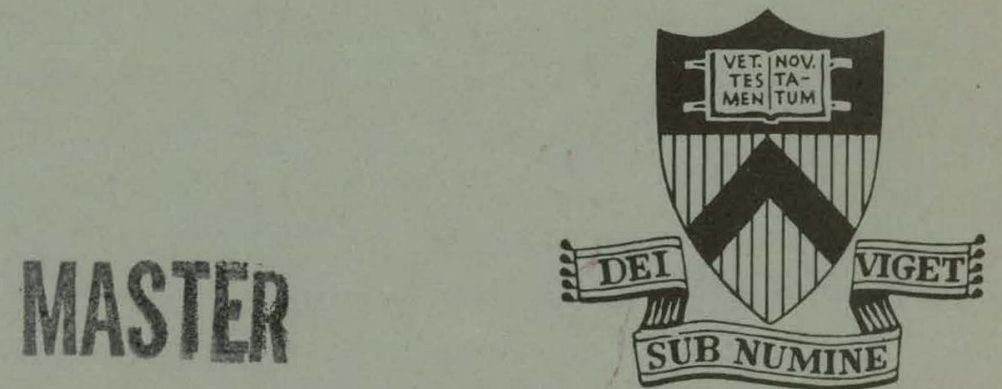

\section{PRINCETON UNIVERSITY PRINCETON, NEW JERSEY}

This work was supported by U. S. Atomic Energy Commission Contract AT (11-1)-3073. Reproduction, translation, publication, use, and disposal, in whole or in part, by or for the United States Covernment is permitted. 


\section{DISCLAIMER}

This report was prepared as an account of work sponsored by an agency of the United States Government. Neither the United States Government nor any agency Thereof, nor any of their employees, makes any warranty, express or implied, or assumes any legal liability or responsibility for the accuracy, completeness, or usefulness of any information, apparatus, product, or process disclosed, or represents that its use would not infringe privately owned rights. Reference herein to any specific commercial product, process, or service by trade name, trademark, manufacturer, or otherwise does not necessarily constitute or imply its endorsement, recommendation, or favoring by the United States Government or any agency thereof. The views and opinions of authors expressed herein do not necessarily state or reflect those of the United States Government or any agency thereof. 


\section{DISCLAIMER}

Portions of this document may be illegible in electronic image products. Images are produced from the best available original document. 
IAEA-CN-33/G1-4

The Princeton Reference Design

Fusion Power Piant

\author{
William G. Price, Jr. \\ Plasma Physics Laboratory, Princeton University \\ Princeton, New Jersey 08540 USA
}

\title{
ABSTRACT
}

The Princeton Reference Design Fusion Power Plant is an electrical generating station based upon a large Tokamak confining a D-T plasma. The plasma major and minor radii are nominally $10.5 \mathrm{~m}$ by $3.2 \mathrm{~m}$; the toroidal field at the center-line is $6 \mathrm{~T}$. With a mean ion temperature of $30 \mathrm{keV}$, an average $\beta$ of 0.04 , and an average $\tau$ of $3.83 \mathrm{~s}$ a fusion power of $3440 \mathrm{MW}$ is achieved during 97 minutes of the 100 minute long-pulse cycle. The plasma throughput of $2.8 \times 10^{22}$ ions/s is deflected down a divertor channel where it cools by radiation and is neutralized, exhausting as hot gas to the vacuum pumps.

The total thermal power of $5305 \mathrm{MW}$ is carried by a helium coolant to a conventional steam cycle producing 2030 MWe net. Tritium is bred in an $80 \mathrm{~cm}$ thick blanket of eutectic flibe ( $53.1 \%$ beryllium fluoride and $46.9 \%$ lithium fluoride) with Nimonic PE-16 (43\% nickel, 39\% iron, $18 \%$ chromium) as the structural material; the blanket-averaged volume fractions are $69.8 \%$ flibe, 9.4\% PE-16, and $20.8 \%$ helium. The breeding ratio of 1.04 will allow doubling of the $2.57 \mathrm{~kg}$ inventory in 121 days. The nominal wall load of $1.76 \mathrm{MW}$ of DT neutrons per $m$ implies a total flux of $8.65 \times 10^{18} \mathrm{n} / \mathrm{m}^{2} \cdot \mathrm{s}$ at the wall and a corresponding helium production rate of $275 \mathrm{ppm} /$ year. 


\section{INTRODUCTION}

During the past two years the Reactor Studies Group of the Princeton Plasma Physics Laboratory has been engaged in the conceptual design of a fusion-based electrical generating station. The study. has been completed; this paper summarizes the guiding principles and the design features incorporated in the resulting power plant. A report [1] is available that describes the Reference Design in great detail.

The basic motivation for this project was a desire to determine what, other than basic plasma physics, might delay the introduction of fusion power. Consequently the ability to confine a plasma was taken for granted, and the various technological aspects of a power plant deriving its energy from fusion have been investigated. An attempt has been made to relate each part of the design to the others in a self-consistent manner so that advantages are not claimed at the expense of hidden problems. It is hoped that studies such as this one will identify those areas of technology that require special development in parallel with the plasma physics research effort.

In keeping with this, a principal guideline has been to use current technology wherever possible (where "current" allows for reasonable developments in the fission reactor program). Thus the Princeton Reference Design represents a first-generation power plant rather than an advanced, optimized one (as, e.g. in Ref. 2). It should provide a basis of comparison with other proposed fusion devices [3,4] as well as with the other advanced energy systems proposed for the turn-of-the-century.

\section{COILS AND PLASMA}

The reactor in the power plant is assumed to be a large Tokamak, because of the recent advances in plasma confinement in such devices. The nominal plasma major and minor radii are $10.5 \mathrm{~m}$ by $3.2 \mathrm{~m}$. The toroidal field, provided by 48 large D-shaped coils, is $6 \mathrm{~T}$ at the centerline and reaches a maximum of $16 \mathrm{~T}$ at the inside of the torus. The D-coils are made of $1600 \mathrm{~km}$ of $\mathrm{Nb}_{3} \mathrm{Sn}$ superconducting ribbon dynamically stabilized with copper. The use of $\mathrm{Nb}-\mathrm{Sn}$ is required to achieve the $16 \mathrm{~T}$ peak toroidal field, but it would be justified regardless because of its. Iower projected cost (relative to Nb-Ti). $\mathrm{Nb}-\mathrm{Sn}$ has been used for all the other coils in the Reference Design. The toroidal field coils carry 315.4 MA-turns of current and store 250 GJ of magnetic energy. A central support column bears the centering force of $50.8 \mathrm{Gg}$ per coil.

The 14.6 MA plasma discharge current is maintained by changing the magnetic flux through the plasma ring. This is done by varying the current in a set of coils. wrapped the "long way" around the torus outside the toroidal field coils. The vertical stabilizing field is produced primarily by 
another set of coils wrapped around the torus near the plasma, inside the D-coils. The poloidal field configuration with its single-null separatrix is produced by these coils together with the plasma current and another pair of elongated coils near the divertor.

The positions and relative currents in all of these poloidal field coils are indicated in Figure 1. Altogether they require $860 \mathrm{~km}$ of $\mathrm{Nb}-\mathrm{Sn}$ ribbon, carrying $112.1 \mathrm{MA}-\mathrm{turns}$ of current. $4.55 \times 10^{5} \mathrm{~m}^{3}$ of helium (STP) is required as the cryogenic coolant fluid. The refrigeration load of $280 \mathrm{~kW}$ at $8 \mathrm{~K}$ is due to thermal conduction ( $150 \mathrm{~kW})$, neutron and gamma heating $(95 \mathrm{~kW})$, and eddy currents from the field pulsing $(35 \mathrm{~kW})$.

The reactor is intended to operate on a long-pulse cycle with 97 minutes of quasi-equilibrium burn and 3 minutes for shutdown, field reversal, and re-ignition. Figure 2 shows the plasma temperature profiles during the burn phase, with 'corresponding density profiles in Figure 3. The mean ion density is $5 \times 10^{19} / \mathrm{m}^{3}$; the mean ion temperature is $30 \mathrm{keV}$. Operation in a thermally stable regime with this low temperature is attained by admixture of up to $4.8 \%$ argon, which enhances the bremsstrahlung. The average $\beta$ is $4 \%$, with a maximum of $13 \%$; the average $\beta_{\theta}$ is 1.83 . The nominal safety factor $q$ is 2.067 .

Since the mean ion confinement time is assumed to be on 1y 3.83 seconds (several hundred Bohm-times confinement) a continuous fuel feed is required. This is attained by the high velocity ballistic injection of solidified fuel pellets of a variety of sizés, chosen to produce a desireable fuelling profile. The fuel requirement is $1.40 \times 10^{22}$ tritons/sec, an equal rate of deuterons, and $0.134 \times 10^{22}$ argon atoms/sec. The DT reaction rate is $1.22 \times 10^{2} / \mathrm{sec}$, for a burnup of $8.7 \%$ per pass.

The boundary condition for the main plasma is set by the temperaturc at the separatrix, around $500 \mathrm{eV}$. Ions diffusing across the separatrix are guided by the divertor field lines into the arms of the divertor channels (see Figure 4) where they radiate most of their energy to the walls. This flow eventually neutralizes and enters the exhaust chamber as a hot supersonic gas, thereby decoupling the plasma from the vacuum pumping system. Another main function of the divertor is to shield the plasma from impurities by ionizing and sweeping away any neutrals which might be knocked off the walls of the chamber.

The placement of the single null of the separatrix on the plane of symmetry is optimal from the standpoint of providing proper poloidal field curvature for MHD stability. It also allows placement of the exhaust chambers in the elongated ends of the moment-free D-shaped toroidal field coils. This configuration contributes, however, to the large 
size of the reactor, because of the need to provide sufficient shielding between the divertor channels and the cryogenic coils. (Of course, the scalings of gross power, wall load, and capital cost tend to increase the size also.)

\section{BLANKET}

The choice of DT fusion entails the production of tritium by reactions of the DT neutrons with lithium. Accordingly a blanket of flibe, cooled with helium, with a "stainless steel" structure surrounds the plasma. This set of materials was felt to be a practical combination and a more conservative choice than the previously accepted refractory metal structure with molten lithium as both breeder and coolant.

The blanket is $80 \mathrm{~cm}$ thick and consists of a large tank of flibe, fronted by a vacuum and (plasma) radiation shield wall (at $r=360 \mathrm{~cm}$ ), and penetrated by tubing for the helium. The flibe composition is the eutectic (53.1\% beryllium fluoride and $46.9 \%$ lithium fluoride), to allow the lowest inlet coolant temperature. The structural material is Nimonic PE-16, an austenitic alloy (43\% nickel, $39 \%$ iron, $18 \%$ chromium) with good fabricability, corrosion resistance, high-temperature strength, and radiation damage resistance. The helium is pressurized to $5.2 \mathrm{MPa}$ (50 atm) to improve its heat transfer properties. The blanket-averaged volume fractions are $69.8 \%$ flibe, $9.4 \% \mathrm{PE}-16$, and $20.8 \%$ helium, with lower fractions of flibe near the wall where greater cooling is required.

The nominal wall load of $1.76 \mathrm{MW} / \mathrm{m}^{2}$ of DT neutrons establishes the source condition for calculations of the neutron flux in the blanket; spectra at several points are shown in Figure 5. The total flux at the wall, $r=360 \mathrm{~cm}$, is $8.65 \times 10^{18} \mathrm{n} / \mathrm{m}^{2} \cdot \mathrm{s}$, of which $3 \times 10^{18} \mathrm{n} / \mathrm{m}^{2} \cdot \mathrm{s}$ is due to neutrons with energies above $1 \mathrm{MeV}$. This intense flux will cause the production of $275 \mathrm{ppm} /$ year of helium in the PE-16, constituting a very severe radiation damage problem. It will also cause a substantial transmutation of the structural material, but fortunately few of the activation products have very long halflives.

The net tritium breeding ratio for this blanket is 1.04, which is more than adequate. The total inventory of tritium is only $2.57 \mathrm{~kg}$ (of which $2.02 \mathrm{~kg}$ is in the fuel feed reserve), so the projected doubling time is 121 days. The parasitic loss of neutrons to the structural material and the fluorine is compensated for by neutron multiplication in the beryllium; excessive breeding is traded-off for extra energy production in the form of capture gammas. 
In the Reference Design the gross thermal power is $5305 \mathrm{MW}$, of which $688 \mathrm{MW}$ derives from the fusion alphas and is radiated to the plasma chamber walls. The remainder is nuclear heating in the blanket; there is a $68 \%$ multiplication of the $14 \mathrm{MeV}$ kinetic energy of the fusion neutrons.

\section{BALANCE OF PLANT}

There are two principal loops out of the reactor blanket. The first passes the flibe through gas disengagers (spray nozzles into evacuated tanks) at a circulation rate of about one turnover every two hours. The bred tritium is removed in this cycle as tritium fluoride, which is electrolyzed, purified, and sent to the fuel reserve system. The slow flow of the flibe enhances heat transfer to the helium coolant, and also feeds a "salt-pot" thermal flywheel which sustains the reactor output during the 3 minute plasma shutdown.

'l'he helium flows through the blanket at a rate of $3.24 \mathrm{Mg} / \mathrm{s}$, exiting at $910 \mathrm{~K}\left(1180^{\circ} \mathrm{F}\right)$, the operating limit of the structural material. An oxygen pressure of $5 \times 10^{-3}$ atm is maintained in the coolant helium to promote the oxidation of any tritium which permeates the coolant tubes. The vapor pressure of the resulting water vapor is held below $10^{-5} \mathrm{~atm}$ by passing a drag stream through dessicants, thereby keeping the tritium activity in the helium very low. By this scheme a chemical barrier greatly reduces the loss of tritium from the reactor by permeation through the steam generators; such losses should be less than $6 \mathrm{Ci} / \mathrm{day}$.

A conventional steam cycle is used to produce electricity, although the option of using direct-cycle gas turbines would seem very attractive. Primary steam is developed at $25.4 \mathrm{MPa}(3690 \mathrm{psi})$ and $810 \mathrm{~K}\left(1000^{\circ} \mathrm{F}\right)$ in an HTGR-type steam generator. Two reheat stages regain the same temperature, but at lower pressures. The steam drives a cross-compound $3600 \mathrm{rev} / \mathrm{min}$ turbine generator combination with one very high pressure, one high pressure, two intermediate pressure, and four low pressure turbines on two 60 meter shafts. The gross electrical conversion efficiency is $43.4 \%$. However, the station internal requirements are $375 \mathrm{MW}$, of which $251 \mathrm{MW}$ are for the helium circulators, leading to a net plant efficiency of $38.3 \%$ and net output of 2030 MWe.

The total capital cost of the Reference Design (in 1974 dollars) is estimated to be $\$ 1215230000$, or roughly $599 \$ / \mathrm{kWe}$. Of this, only $\$ 403050000$ is due to the nuclear island. The cost of busbar energy is estimated as $15.5 \mathrm{mills} / \mathrm{kW} \cdot \mathrm{hr}$, based on a $15 \%$ return on investment, $85 \%$ plant availability, $3.1 \mathrm{mills} / \mathrm{kW} \cdot \mathrm{hr}$ for operation and maintenance, and negligible cost of fuel. 


\section{CONCLUSIONS}

A principal purpose of this study was to identify research areas which would be most important for the early introduction of fusion power. To this end, current technology was exploited wherever possible, so that essential extensions would stand out. These include the following: that large size high-field $\mathrm{Nb}-\mathrm{Sn}$ superconducting coils can be built; that a long-pulse tokamak can be continuously fueled; that the divertor will screen out impurities and channel out the exhaust; that the radiation damage resistance of austenitic materials can be improved by an order of magnitude; and that fail-safe sealed systems for processing large amounts of tritium can be developed.

Fortunately, none of these problems or the others encountered seem unsolvable on a realistic development timescale (with a prototype plant in the mid 1990's).

\section{ACKNOWLEDGMENTS}

This paper is only a brief summary of the work performed by at least fifteen members of the PPPL Reactor Studies Group under the leadership of Dr. R. G. Mills.

This work was supported by U.S. Atomic Energy Commission Contract AT(11-1)-3073 and by The Edison Electric Institute (Project RP 113). 


\section{REFERENCES}

[1] MILLS, R. G., ed., "A Fusion Power Plant,". Princeton

Plasma Physics Laboratory Report MATT-1050 (1974)

[2] FRAAS, A. P., "Conceptual Design of the Blanket and Shield Region and Related systems for a Full scale Toroidal Fusion Reactor," Oak Ridge National Laboratory Report ORNL-TM-3096 (1973).

[3] BADGER, B., et al., "UWMAK-1: A Wisconsin Toroidal Fusion Reactor Design," University of Wisconsin Nuclear Engineering Department Report UWFDM-68 (1973).

[4] "An Engineering Design Study of a Reference Theta-Pinch Reactor (RTPR)," Vol. I, Los Alamos Scientific Laboratory Report LA-5336 and Argonne National Laboratory Report ANL-8019 (1974).

\section{$Z$ METERS}

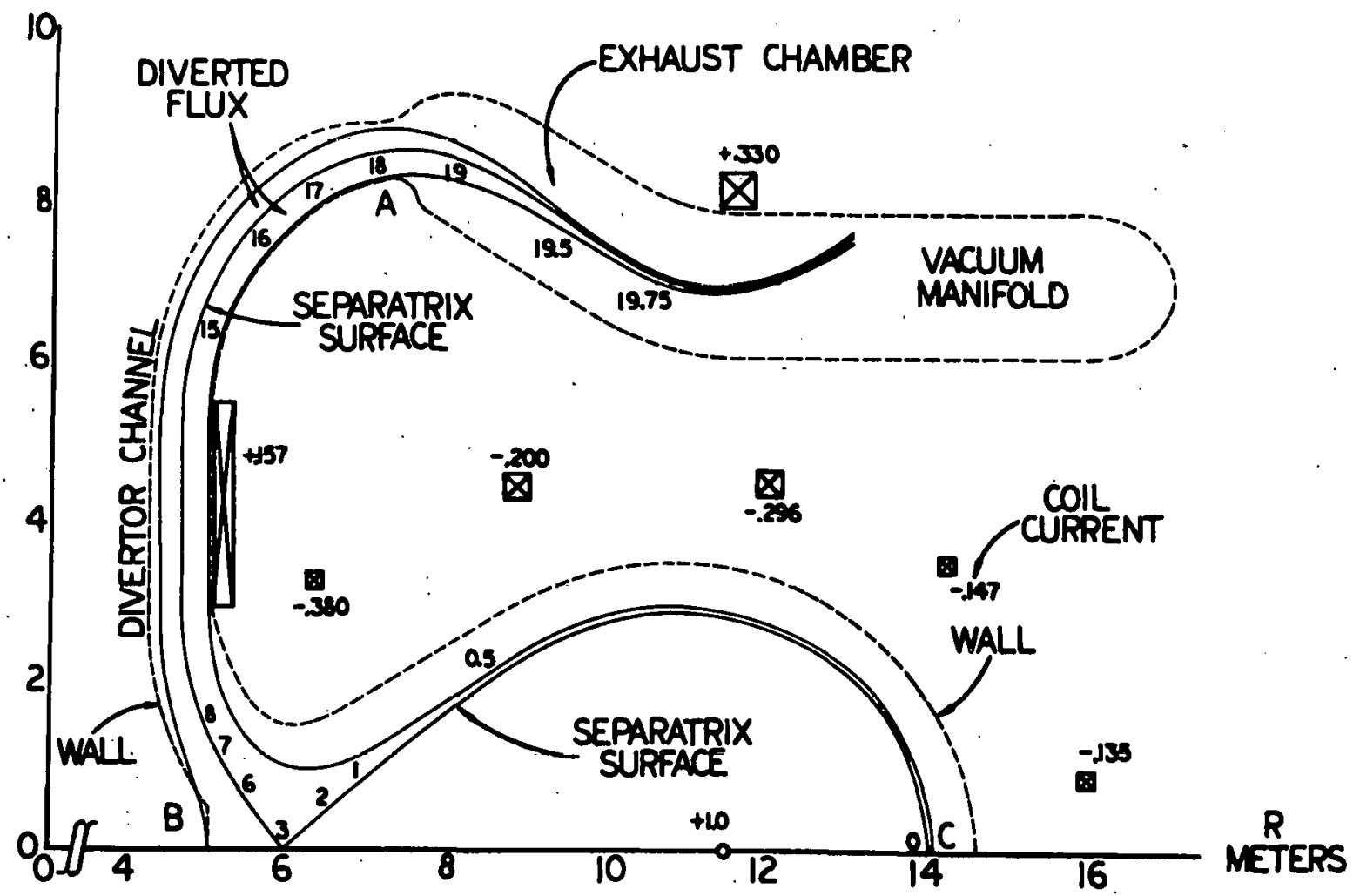

734445

Fig. 1. Magnetic flux surfaces and poloidal field coils. 


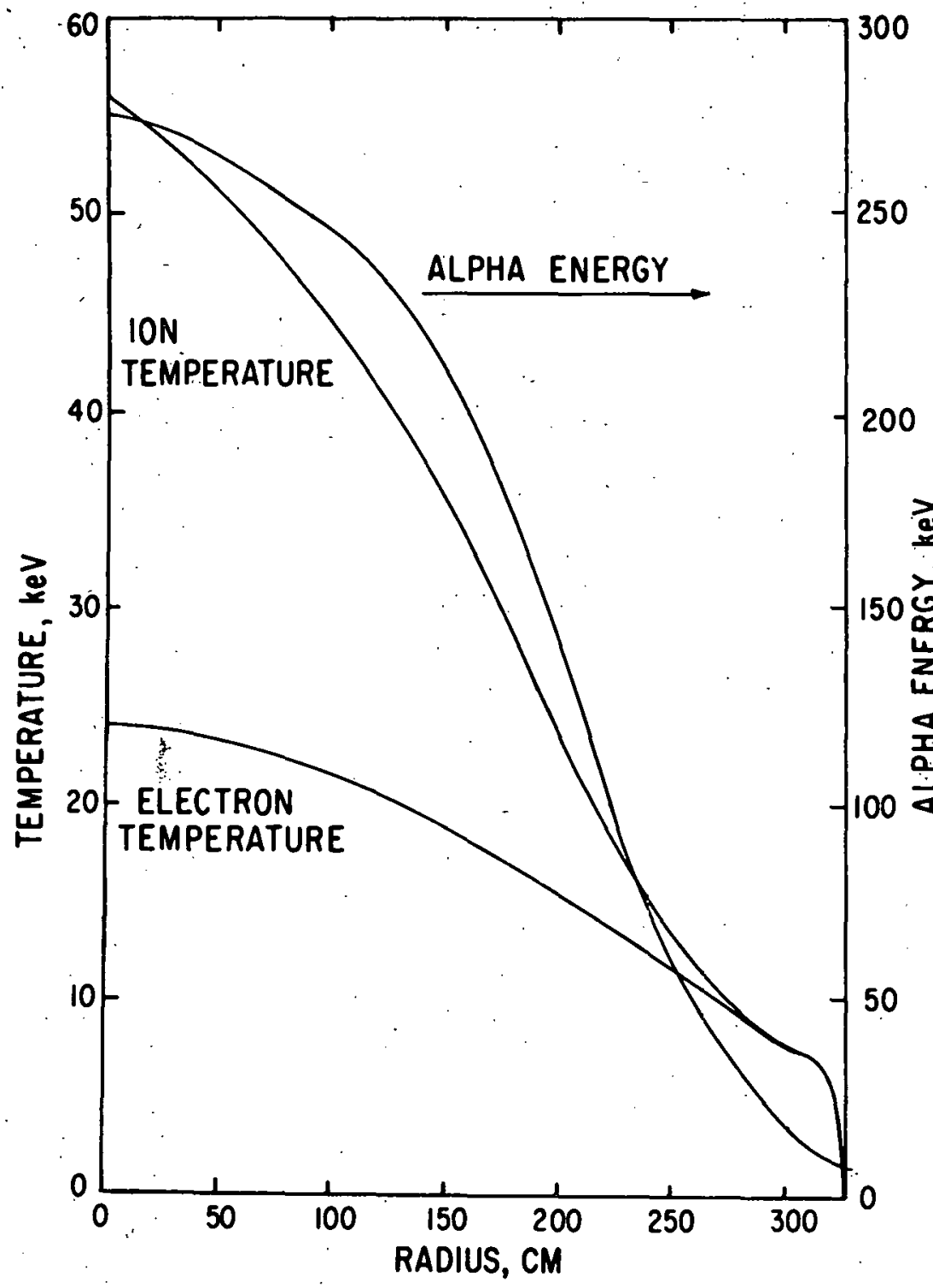

744305

Fig. 2. Temperature profiles

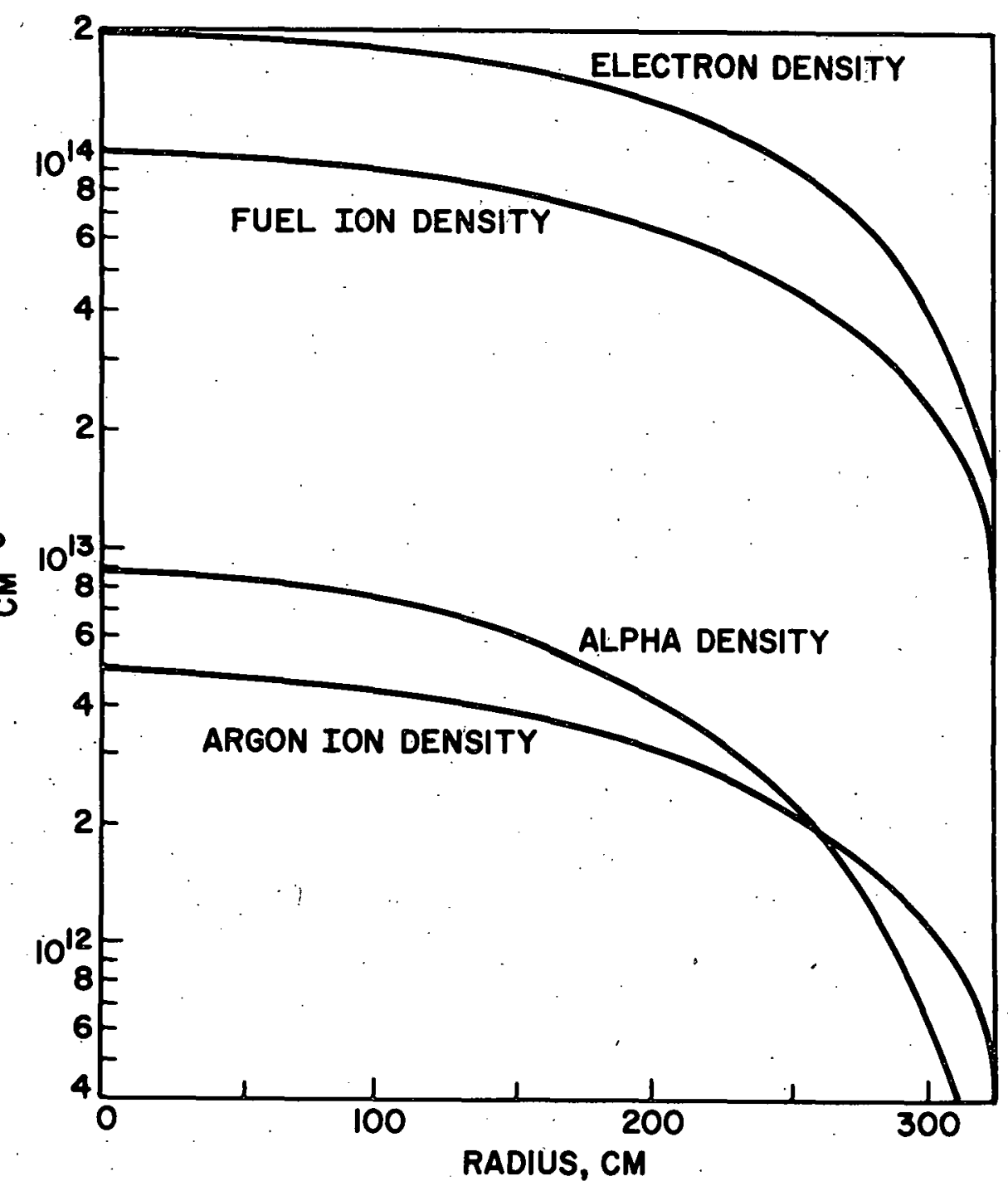

744304

Fig. 3. Density profiles 


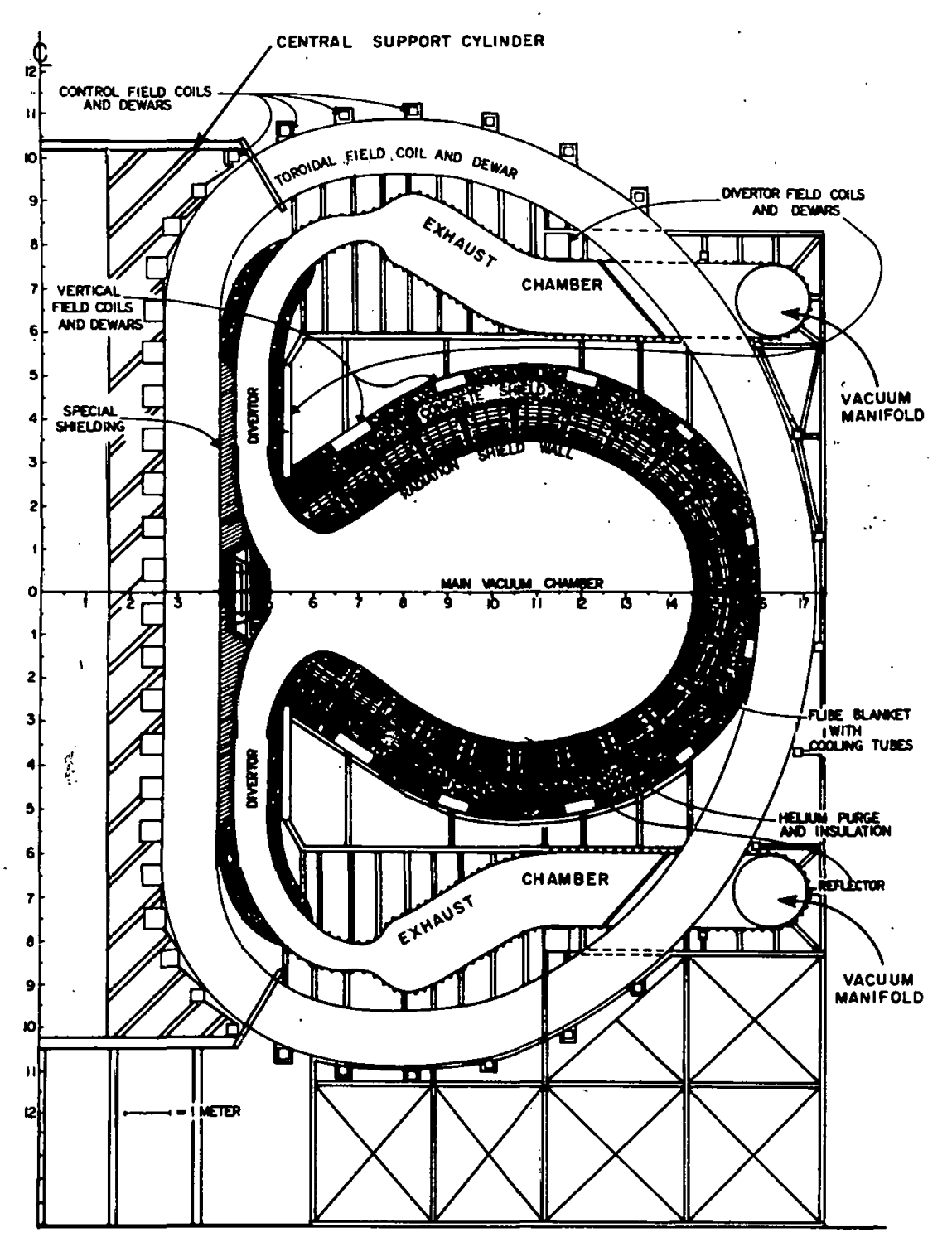

744378

Fig. 4. Cross section of the nuclear island.

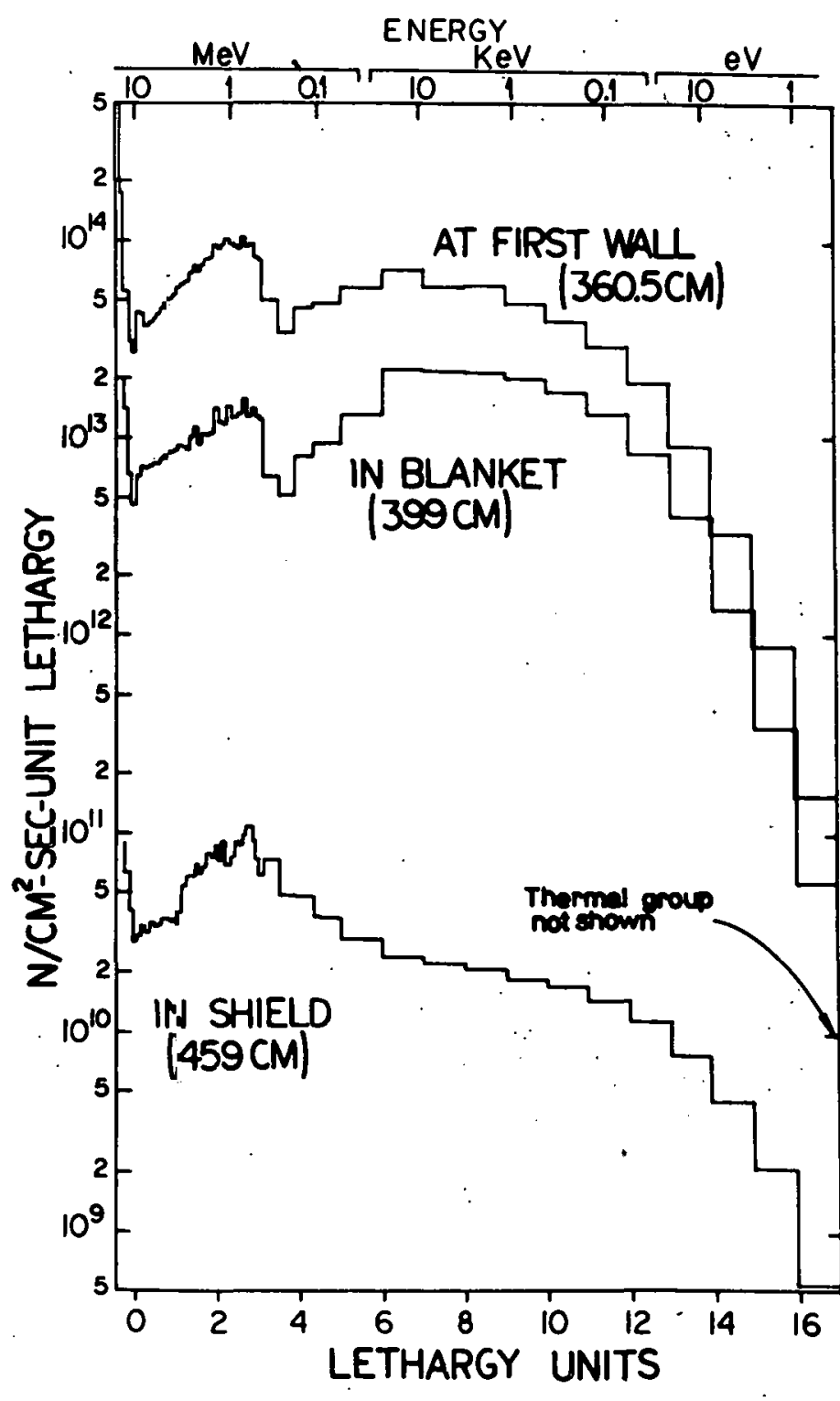

734304

Fig. 5. Neutron flux spectra. 
LEGAL NOTICE-

This report was prepared as an account of Government sponsored work. Neither the United States, nor the Commission, nor any person acting on behalf of the commission:

A. Makes any warranty or representation, express or implied, with respect to the accuracy, completeness, or usefulness of the information contained in this report, or that the use of any information, apparatus, method, or process disclosed in this report may not infringe privately owned rights; or

B. Assumes any liabilities with respect to the use of, or for damages resulting from the use of any information, apparatus, method, or process disclosed in this report.

As used in the above, "person acting on behalf of the Commission" includes any employee or contractor of the Commission to the extent that such employee or contractor prepares, handles or distributes, or provides access to, any information pursuant to his employment or contract with the Commission. 